Article

\title{
Regional Vicarious Calibration of the SWIR-Based Atmospheric Correction Approach for MODIS-Aqua Measurements of Highly Turbid Inland Water
}

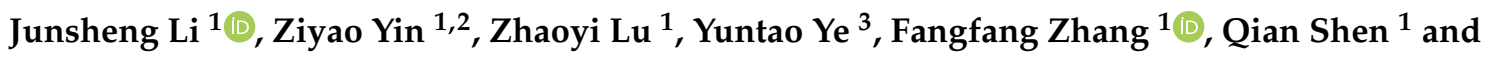 \\ Bing Zhang 1,2,*(D) \\ 1 Key Laboratory of Digital Earth Science, Aerospace Information Research Institute, \\ Chinese Academy of Sciences, Beijing 100094, China \\ 2 University of Chinese Academy of Sciences, Beijing 100049, China \\ 3 State key Laboratory of Simulation and Regulation of Water Cycle in River Basin, China Institute of Water \\ Resources and Hydro Power Research, Beijing 100038, China \\ * Correspondence: zb@radi.ac.cn
}

Received: 4 June 2019; Accepted: 12 July 2019; Published: 13 July 2019

check for updates

\begin{abstract}
Water color remote sensing requires accurate atmospheric correction but this remains a significant challenge in highly turbid waters. In this respect, the shortwave infrared (SWIR) band-based atmospheric correction approach has proven advantageous when applied to the moderate resolution imaging spectroradiometer (MODIS) onboard the Aqua satellite. However, even so, uncertainties affect its accuracy. We performed a regional vicarious calibration of the MODIS-Aqua SWIR $(1240,2130)$-based atmospheric correction using in situ water surface reflectance data measured during different seasons in Lake Taihu, a highly turbid lake. We then verified the accuracy of the (1240, 2130)-based atmospheric correction approach using these results; good results were obtained for the remote sensing reflectance retrievals at the 555, 645 , and $859 \mathrm{~nm}$, with average relative errors of $15 \%$, $14 \%$, and $22 \%$, respectively, and no significant bias. Comparisons with the $(1240,2130)$-based iterative approach and $(1640,2130)$-based approach showed that the vicarious calibrated $(1240,2130)$-based approach has the best accuracy and robustness. Thus, it is applicable to the highly turbid Lake Taihu. It may also be applicable to other highly turbid inland waters with similar optical and aerosol optical properties above water, but such applications will require further validation.
\end{abstract}

Keywords: vicarious calibration; atmospheric correction; MODIS-Aqua; Lake Taihu; SWIR

\section{Introduction}

Water color satellite sensors receive top-of-atmosphere (TOA) radiance, which includes water-leaving and atmospheric path radiance. Water-leaving radiance, which can be used to assess water parameters, must be derived from satellite-received TOA radiance [1]. This process is known as atmospheric correction, which is the basis for water color remote sensing. Gordon and Wang [1] proposed an atmospheric correction approach (abbreviated as GW94) based on the "black near-infrared (NIR) water-leaving radiance" assumption. This approach uses two NIR bands to assess aerosol radiance and then interpolates the aerosol radiance to visible (VIS) bands. Previous studies have applied this approach to the sea-viewing wide field-of-view sensor (SeaWiFS) and the moderate-resolution imaging spectroradiometer (MODIS), which have all yielded good results in open ocean waters [2]. For turbid coastal and inland waters, however, the near-infrared water-leaving radiance is apparently greater than zero and, therefore, the "black NIR" assumption is no longer valid. Therefore, the GW94 approach fails to perform accurate atmospheric correction in turbid water. Using the "black NIR"-based approach, studies have developed a number of improved methods for turbid waters, which include 
two main categories. The first attempts to develop models to assess the water-leaving radiance in NIR bands mainly using an iterative approach [3-7]. The second approach uses atmospheric information derived from adjacent clear water and interpolates the corrections to the turbid water [8]. These improved approaches usually work well in moderately turbid waters but are not necessarily valid for highly turbid waters since certain waters saturate the NIR bands, rendering these "black NIR"-based approaches completely unusable.

Wang and Shi [9-11] proposed a "black shortwave infrared (SWIR)"-based approach, which assumes that the water-leaving radiance in the SWIR bands is zero and uses two SWIR bands to replace the two NIR bands present in the original GW94 approach. Due to the strong absorption at the SWIR wavelengths from pure water [12], the water-leaving radiance in the SWIR wavelength for even highly turbid water tends to be zero. Therefore, the SWIR-based atmospheric correction approach can be used for highly turbid waters. Previous studies have already verified this approach with its application to MODIS-Aqua data in several areas with highly turbid water, including the East China Sea and eastern coast of the U.S.A. $[9,10,13,14]$. These studies used two SWIR bands at 1240 and 2130 nm because 14 out of the 20 detectors for the original $500 \mathrm{~m}$ resolution $1640 \mathrm{~nm}$ band on the MODIS-Aqua are inoperable. However, in certain highly turbid waters, such as areas in Lake Taihu, we cannot neglect the water-leaving radiance at the $1240 \mathrm{~nm}$ band and the original $(1240,2130)$ SWIR-based atmospheric correction approach will overestimate aerosol scattering and underestimate the water-leaving radiance in the visible and NIR bands. To solve this problem, Wang et al. [15] proposed an iterative approach and used the relatively clear water pixels at the center of Lake Taihu to retrieve an aerosol model from the original $(1240,2130)$ SWIR band-based atmospheric correction and interpolated the aerosol model to the entire lake. With the interpolated aerosol model and the $2130 \mathrm{~nm}$ band determined aerosol scattering, they then performed atmospheric correction for the entire lake. Zhang et al. [16] suggested that the center of Lake Taihu is not always relatively clear and, therefore, revised the iterative approach by selecting the 200 pixels with the clearest water in the entire lake, as opposed to only the middle area of the lake. However, there are still several uncertainties in the (1240, 2130)-based iterative method. Lake Taihu is a large lake, with an area of over $2300 \mathrm{~km}^{2}$, surrounded by large metropolitan areas, such as Suzhou, Wuxi, Changzhou, and Huzhou. Therefore, aerosol models applicable above the entire lake may significantly change in certain circumstances. Otherwise, locating relatively clear water in Lake Taihu is not always easy, which leads to the failure of the $(1240,2130)$-based iterative method. To avoid these uncertainties, Wang et al. [17] replaced the $1240 \mathrm{~nm}$ band with the $1640 \mathrm{~nm}$ band and applied the (1640, 2130)-based atmospheric correction approach because the water-leaving radiance at $1640 \mathrm{~nm}$ is more likely to be near zero due to higher water absorption at longer wavelengths. However, since $70 \%$ of the detectors for the original $500 \mathrm{~m}$ resolution $1640 \mathrm{~nm}$ band on the MODIS-Aqua are inoperable, the (1640, 2130)-based method cannot be applied operationally.

Except for the uncertainties mentioned above, there are a number of other uncertainties associated with the atmospheric correction of water color remote sensing images. To improve the accuracy of atmospheric correction, previous studies have widely adopted vicarious calibration as an operational method [18-25]. Vicarious calibration uses the in situ-measured water-leaving radiance coincident with the water color remote sensing images to compute the vicarious calibration coefficients, i.e., the gains, to obtain the original TOA radiance of the water color remote sensing images. Vicarious calibration can cancel out the error sources and uncertainties in the atmospheric correction process, thus improving atmospheric correction accuracy. For open ocean waters, studies have performed reliable vicarious calibrations based on the in situ water-leaving radiance measured by the marine optical buoy (MOBY) [20,26]. The vicarious calibration coefficients for MODIS-Aqua have been previously applied to the operational processing of MODIS-Aqua data. However, these calibration coefficients are applicable to clear open ocean waters when using the NIR-based atmospheric correction approach but may not be suitable for highly turbid waters when using the SWIR-based atmospheric correction approach. Therefore, to improve the accuracy of the SWIR-based atmospheric correction approach in highly turbid waters, we recommend the vicarious calibration of the SWIR-based atmospheric correction approach 
for highly turbid waters. In this study, we performed regional vicarious calibration of MODIS-Aqua data over highly turbid waters using the SWIR-based atmospheric correction approach. We used in situ water surface reflectance data measured in the highly turbid Lake Taihu during different seasons to perform the vicarious calibration of the $(1240,2130)$-based atmospheric correction approach. We then verified the accuracy of the $(1240,2130)$-based atmospheric correction approach with the vicarious calibrated results.

\section{Study Area and Data Description}

\subsection{Study Area Description}

Lake Taihu in eastern China was selected as the study area (Figure 1). It is the third largest freshwater lake in China and has an area of over $2300 \mathrm{~km}^{2}$ [27]. Lake Taihu is a highly turbid lake, with an average concentration of total suspended matter that is greater than $50 \mathrm{mg} \mathrm{L}^{-1}$ and a maximum concentration of total suspended matter that is greater than $300 \mathrm{mg} \mathrm{L}^{-1}$ [28]. Taihu Lake is located in the core area of the middle and lower reaches of the Yangtze River, and is the source of drinking for surrounding cities such as Wuxi and Suzhou. In recent years, the water properties of Lake Taihu have attracted significant attention for remote sensing data studies [16,17,28-37].

From 2005 to 2014, we performed 12 cruise surveys of Lake Taihu, during which we measured the in situ water surface reflectance at 377 water sampling stations, whose locations are shown in Figure 1. Table 1 lists relevant information, such as the dates and sampling stations, for each cruise survey.

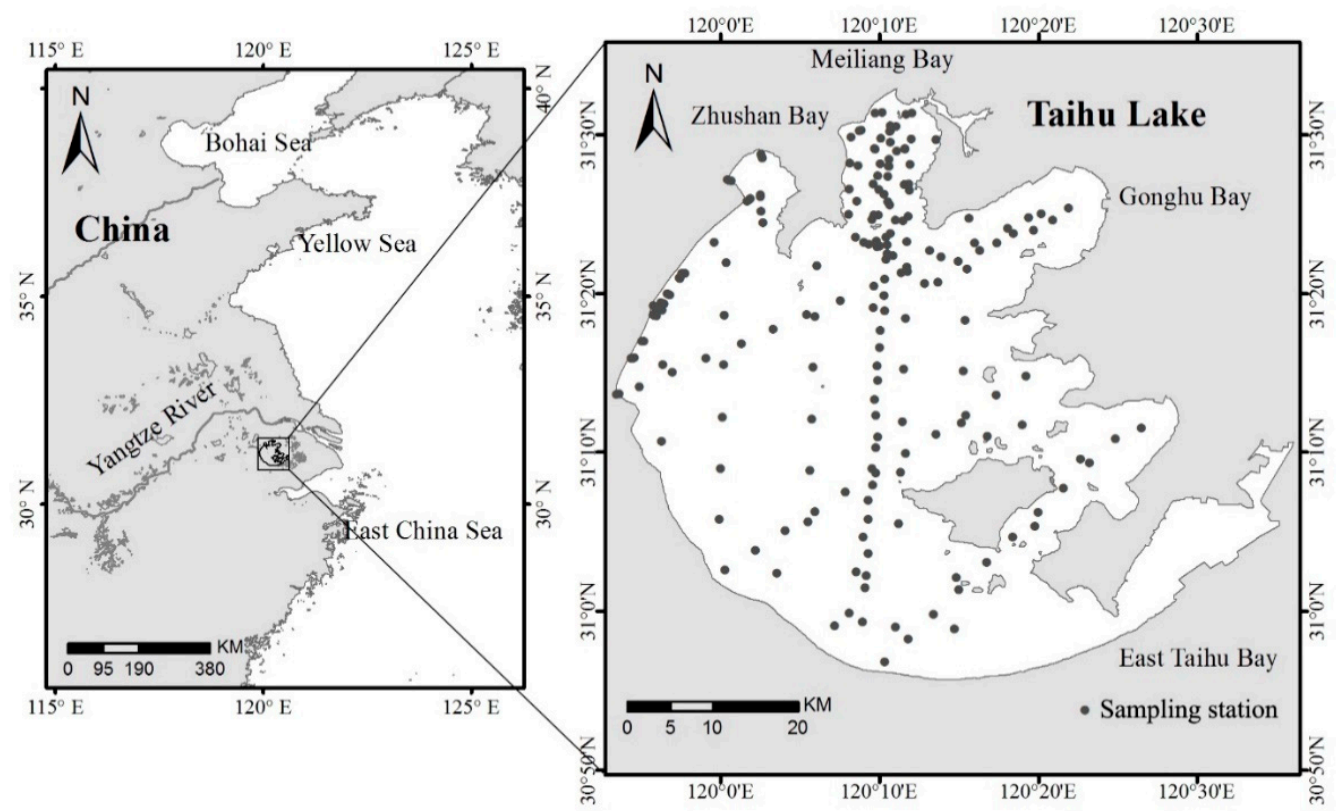

Figure 1. Maps of the location of Lake Taihu, China, and the 377 in situ water sampling stations used during the 12 cruise surveys performed between 2005 and 2014.

Table 1. The dates and sampling stations for each cruise survey performed on Lake Taihu.

\begin{tabular}{cc|cc}
\hline Cruise Dates & Number of Stations & Cruise Dates & Number of Stations \\
\hline Oct. 10, 2005 & 13 & Mar. 14-15, 2009 & 29 \\
Jan. 7-9, 2006 & 47 & Apr. 17-27, 2009 & 51 \\
Jul. 29 to Aug. 1, 2006 & 39 & Oct. 17-18, 2012 & 9 \\
Oct. 12-15, 2006 & 37 & May 11-13, 2013 & 40 \\
Jan. 7-9, 2007 & 50 & Jul. 21-22, 2014 & 8 \\
Apr. 25-27, 2007 & 40 & Oct. 26, 2014 & 14 \\
\hline
\end{tabular}




\subsection{Water Surface Reflectance Measurements}

During the 12 cruise surveys, we measured the in situ water surface reflectance spectra at each sampling station with an ASD portable field spectrometer FieldSpec®Pro VNIR (wavelength range from 350-1,000 nm) and FieldSpec $ß$ Pro FR (wavelength range from 350-2,500 nm) using the above water method [38]. At each station, we measured the standard panel $\left(L_{p}(\lambda)\right)$, water $\left(L_{s w}(\lambda)\right)$, and skylight $\left(L_{s k y}(\lambda)\right)$ on the open deck. With these measurements, we calculated the remote sensing reflectance $\left(R_{r s}(\lambda)\right)$ with the following equation:

$$
R_{r s}(\lambda)=\frac{L_{w}(\lambda)}{E_{d}(\lambda)}=\frac{L_{s w}(\lambda)-r_{s k y} L_{s k y}(\lambda)}{\pi L_{p}(\lambda) / \rho_{p}(\lambda)}
$$

where $\lambda$ is wavelength, $E_{d}(\lambda)$ is the downward irradiance above the water surface, $L_{w}(\lambda)$ is the water-leaving radiance, $\rho_{p}(\lambda)$ is the reflectance of the standard panel calibrated in the laboratory, and $r_{s k y}$ is the skylight reflectance at the air-water interface, which can be determined from the look-up table [39]. Wind speeds at each sampling station were measured simultaneously with reflectance measurements and were used to determine $r_{\text {sky }}$ values.

Figure 2 shows the calculated $R_{r s}$ spectra for the 12 cruise surveys. Previous studies have already applied several of these $R_{r s}$ data to study the water properties of Lake Taihu [24,29,40-42].

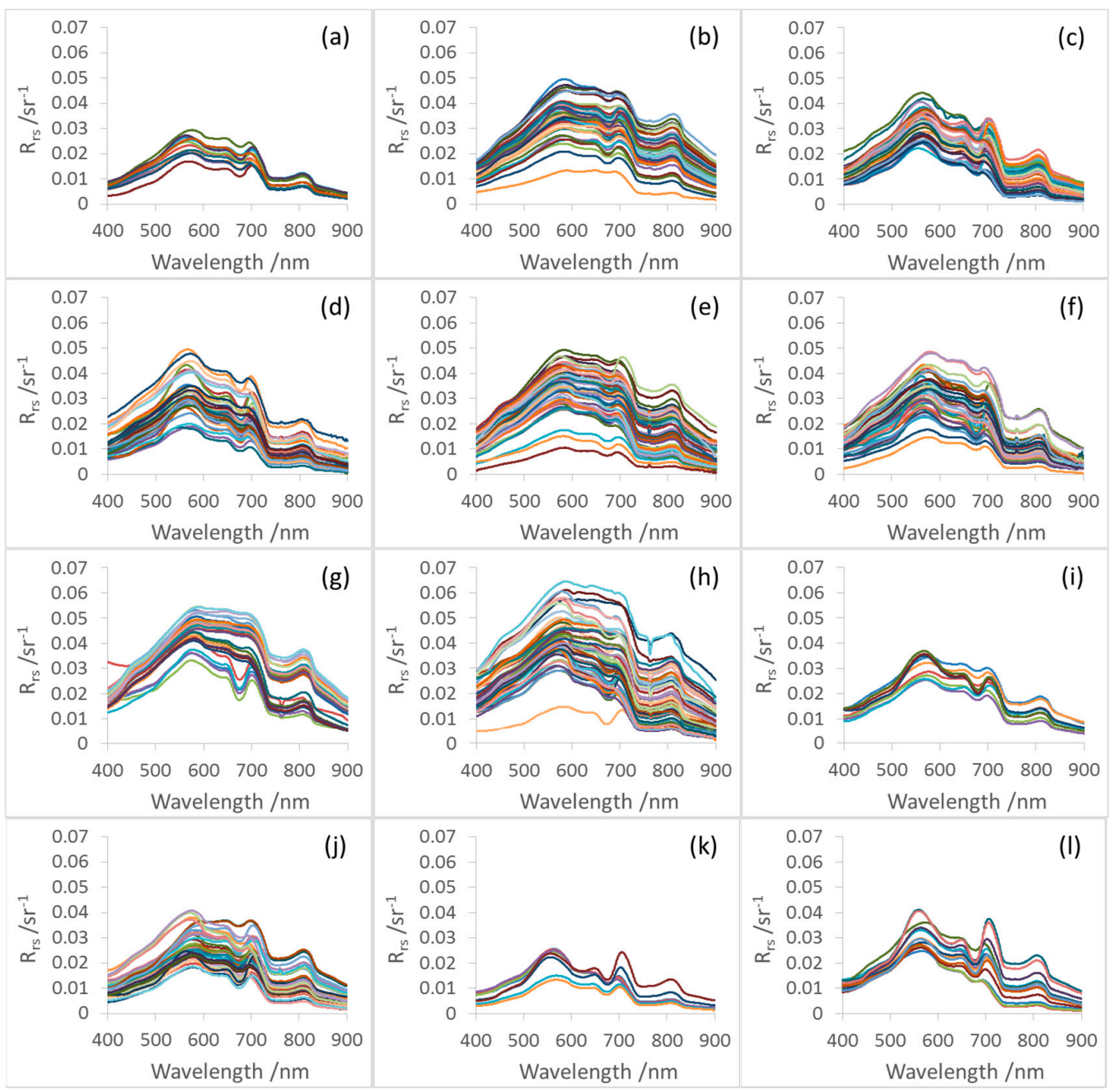

Figure 2. The $R_{\mathrm{rs}}$ spectra measured in Lake Taihu from the 12 cruise surveys performed in (a) October 2005, (b) January 2006, (c) July to August 2006, (d) October 2006, (e) January 2007, (f) April 2007, (g) March 2009, (h) April 2009, (i) October 2012, (j) May 2013, (k) July 2014, and (1) October 2014. 


\subsection{MODIS-Aqua Description}

MODIS, an onboard Aqua satellite, was launched on 4 May, 2002. Of the 36 bands equipped on MODIS, 16 can be used to study water properties, including nine $1 \mathrm{~km}$ spatial resolution ocean color bands (i.e., 412, 443, 488, 531, 547, 667, 678, 748, and $869 \mathrm{~nm}$ ), five $500 \mathrm{~m}$ land bands (i.e., 469, 555, 1240, 1640 , and $2130 \mathrm{~nm}$ ), and two $250 \mathrm{~m}$ bands ( 645 and $859 \mathrm{~nm}$ ). For highly turbid waters, out of the nine ocean color bands, six bands (547, 667, 678, 748, and $869 \mathrm{~nm}$ ) often become saturated and should not be used. The three SWIR bands (i.e., 1240, 1640, and $2130 \mathrm{~nm}$ ) can be used for atmospheric corrections. Finally, the eight other visible and NIR bands (i.e., 412, 443, 469, 488, 531, 555, 645, and $859 \mathrm{~nm}$ ) can be used to study the water properties of highly turbid waters. Out of these eight bands, the four land bands (i.e., 469, 555, 645, and $859 \mathrm{~nm}$ ) have both higher spatial resolution and radiometric dynamic range and are, therefore, more beneficial when studying the water properties of highly turbid coastal and inland waters, because highly turbid waters produce higher reflectance signals than clear waters. In this study, we analyzed the atmospheric correction result accuracy of these eight bands (i.e., 412, $443,469,488,531,555,645$, and $859 \mathrm{~nm}$ ), with a primary focus on the four land bands (i.e., $469,555,645$, and $859 \mathrm{~nm}$ ).

We used coincident in situ remote sensing reflectance data to calibrate and verify the atmospheric correction results of the MODIS-Aqua data, which include 18 scenes of images referred to as: A20060080540, A20060090445, A20062100440, A20062110520, A20062120425, A20070070430, A20070080510, A20070090555, A20071160535, A20090730540, A20091070530, A20091120545, A20091160520, A20122910440, A20122920525, A20131320535, A20142020430, and A20142990510.

\section{Methods}

\subsection{Regional Vicarious Calibration Method}

The water-air radiometric transfer function [20] is given by the following equation:

$$
L_{\mathrm{t}}(\lambda)=\left(t_{\mathrm{dv}}(\lambda) L_{\mathrm{w}}(\lambda)+L_{\mathrm{a}}(\lambda)+L_{\mathrm{r}}(\lambda)+t L_{\mathrm{f}}(\lambda)+T L_{\mathrm{g}}(\lambda)\right) \operatorname{tg}_{\mathrm{gs}}(\lambda) t_{\mathrm{gv}}(\lambda) f_{\mathrm{p}}(\lambda)
$$

where $L_{\mathrm{t}}(\lambda), L_{\mathrm{a}}(\lambda), L_{\mathrm{r}}(\lambda), t L_{\mathrm{f}}(\lambda)$, and $T L_{\mathrm{g}}(\lambda)$ are the TOA radiance, aerosol scattering radiance, which includes Rayleigh-aerosol interactions, Rayleigh scattering radiance (air molecule scattering), surface whitecap radiance, and sunglint, respectively; $t_{\mathrm{dv}}(\lambda)$ is the water surface to satellite diffuse transmittance; $t_{\mathrm{gv}}(\lambda)$ and $t_{\mathrm{gs}}(\lambda)$ are the gaseous absorption from the water surface to the sensor and Sun to water surface, respectively; and $f_{\mathrm{p}}(\lambda)$, is the correction coefficient for the band sensor response to the observed radiance polarization.

Vicarious calibration is based on this water-air radiometric transfer function, which uses the coincidently in situ-measured $R_{r s}(\lambda)$ to model $L_{\mathrm{t}}(\lambda)$, followed by regression analysis with the corresponding MODIS-received $L_{\mathrm{t}}(\lambda)$. Before input into Equation (2), the in situ-measured $R_{r s}(\lambda)$ should be transformed to $L_{\mathrm{w}}(\lambda)$ as follows [43]:

$$
\mathrm{L}_{\mathrm{w}}(\lambda)=\mathrm{nL}_{\mathrm{w}}(\lambda)\left(\mathrm{f}_{\mathrm{s}} \cos \left(\theta_{\mathrm{s}}\right) \mathrm{t}_{\mathrm{ds}}(\lambda) \mathrm{f}_{\mathrm{b}}(\lambda)\right)=\left(\mathrm{R}_{\mathrm{rs}}(\lambda)^{*} \mathrm{~F}_{0}(\lambda)\right)\left(\mathrm{f}_{\mathrm{s}} \cos \left(\theta_{\mathrm{s}}\right) \mathrm{t}_{\mathrm{ds}}(\lambda) \mathrm{f}_{\mathrm{b}}(\lambda)\right)
$$

where $\mathrm{n} L_{\mathrm{w}}(\lambda)$ is the normalized water-leaving radiance, $F_{0}$ is the TOA solar irradiance at the average Earth-Sun distance, $f_{\mathrm{s}}$ is the adjustment parameter for changes in the Earth-Sun distance, $\theta_{\mathrm{s}}$ is the solar zenith angle, $t_{\mathrm{ds}}(\lambda)$ is the Sun to water surface diffuse transmittance, and $f_{\mathrm{b}}(\lambda)$ is the water surface bidirectional reflectance correction parameter.

The parameters in Equations (2) and (3) can be computed using the SeaWiFS data analysis system (SeaDAS 7.2) based on the SWIR (1240, $2130 \mathrm{~nm}$ ) atmospheric correction approach. We computed $L_{\mathrm{W}}(\lambda)$ by inputting the coincidently in situ-measured $R_{r s}(\lambda)$ into Equation (3) and then calculated $L_{\mathrm{t}}(\lambda)$ by inputting the computed $L_{\mathrm{W}}(\lambda)$ into Equation (2). We further use the computed $L_{\mathrm{t}}(\lambda)$ and its corresponding MODIS-received $L_{t}(\lambda)$ to perform regression analysis, as shown in Equation (4). We then 
obtained the vicarious calibration coefficients for each band. We note that this regression equation only contains gain $(\lambda)$ but no offset $(\lambda)$ because this is a more stable technique [20].

$$
L_{\mathrm{t}}{ }^{\text {Computed }}(\lambda)=\operatorname{gain}(\lambda) * L_{\mathrm{t}}{ }^{\mathrm{MODIS}}(\lambda)
$$

The in situ $R_{r s}(\lambda)$ spectra data should be convolved into $R_{\mathrm{rs}}\left(\lambda_{\mathrm{i}}\right)$ with the relative spectral response function for each MODIS-Aqua VIS-NIR band before substitution into Equation (3):

$$
R_{r s}\left(\lambda_{i}\right)=\frac{\int_{\lambda_{\min }}^{\lambda_{\max }} R_{r s}(\lambda) f_{\mathrm{i}}(\lambda) d \lambda}{\int_{\lambda_{\min }}^{\lambda_{\max }} f_{i}(\lambda) d \lambda}
$$

where $f_{\mathrm{i}}(\lambda)$ is the relative spectral response function for each MODIS-Aqua band and $\lambda_{\min }$ and $\lambda_{\max }$ are the wavelength range of the spectral response function for each band.

We note that the coincident in situ $R_{r s}(\lambda)$ or $\mathrm{n} L_{\mathrm{w}}(\lambda)$ spectra are key parameters in the vicarious calibration process. Vicarious calibration of the NIR-based atmospheric correction approach often uses the in situ $n L_{\mathrm{w}}(\lambda)$ spectra measured by the marine optical buoy (MOBY) in clear oceanic waters off Hawaii [20]. Vicarious calibration of the SWIR-based atmospheric correction approach can also use MOBY data, which is beneficial for the NIR-SWIR combined atmospheric correction algorithm [23]. However, MOBY data will also yield larger uncertainties due to the low signal-to-noise ratio that characterizes the SWIR bands over clear oceanic waters. Although we are attempting to improve the SWIR-based atmospheric correction accuracy over highly turbid inland waters, such as Lake Taihu, we do not need to consider the combination with the NIR-based atmospheric correction algorithm. Therefore, to reduce uncertainty caused by the low signal-to-noise ratio, we instead used in situ $R_{r s}(\lambda)$ data from the highly turbid Lake Taihu for the vicarious calibration of the SWIR-based atmospheric correction approach. The vicarious calibration results can also counteract local aerosol effects and yield improved accuracy at Lake Taihu, as well as similar adjacent lakes that are highly turbid.

\subsection{Atmospheric Correction Based on Vicarious Calibration Results}

After we obtained the vicarious calibration coefficients for the eight MODIS-AQUA VIS-NIR bands, we substituted them into the SeaDAS7.2 to perform the SWIR-based atmospheric corrections. In the SeaDAS7.2 12gen module, we input the vicarious calibration coefficients for the eight VIS-NIR bands into the "gain" parameters. We note that the "gain" parameters should include 16 numbers for all 16 bands that can be used for water optical property studies, whereas we used the default numbers provided in the SeaDAS7.2 as the "gain" parameters for the other 8 bands. Table 2 lists the "gain" settings, as well as other parameters for the SeaDAS7.2.

Table 2. The SeaWiFS data analysis system (SeaDAS)7.2 parameter settings for atmospheric correction based on the shortwave infrared (SWIR) $(1240,2130)$ combined with the vicarious calibration results. The gain(412), gain(443), gain(469), gain(488), gain(531), gain(555), gain(645), and gain(859) should be replaced with the vicarious calibration results. The other numbers in the "gain" parameter are the default numbers provided in the SeaDAS 7.2. The brdf_opt $=0$ means that the bidirectional reflectance

\begin{tabular}{|c|c|c|}
\hline Parameter & Meaning & Setting \\
\hline gain & Vicarious calibration coefficients & $\begin{array}{c}\text { [gain(412), gain(443), gain(469), gain(488), } \\
\text { gain(531), 0.9989, gain(555), gain(645), 0.9996, }, \\
0.9997, \text { gain(859), } 1,1,1,1]\end{array}$ \\
\hline aer_opt & aerosol calculation mode & -1: Multi-scattering with 2-band model selection \\
\hline aer_wave_short & $\begin{array}{l}\text { Lower wavelength used for aerosol } \\
\text { model selection }\end{array}$ & 1240 \\
\hline aer_wave_long & $\begin{array}{l}\text { Upper wavelength used for aerosol } \\
\text { model selection and aerosol } \\
\text { concentration }\end{array}$ & 2130 \\
\hline
\end{tabular}
distribution function (BRDF) effect is not corrected; this is further discussed in Section 5.1. 
Table 2. Cont.

\begin{tabular}{|c|c|c|}
\hline Parameter & Meaning & Setting \\
\hline cloud_wave & Wavelength used to identify clouds & 2130 \\
\hline cloud_thresh & Threshold used to identify clouds & 0.0175 \\
\hline brdf_opt & $\begin{array}{l}\text { Option for running bi-directional } \\
\text { reflectance correction (BRDF) factor }\end{array}$ & 0 \\
\hline resolution & Spatial resolution of outputs & 250 \\
\hline
\end{tabular}

\subsection{Accuracy Assessment of the Atmospheric Correction Results}

We incorporated the vicarious calibration results into the (1240, 2130)-based atmospheric correction, which we refer to as the $(1240,2130)$-Cal method. To assess the accuracy of the $(1240,2130)$-Cal method, we compared it with the two other methods mentioned previously, i.e., the $(1640,2130)$-based method, which we refer to as the $(1640,2130)$ method, and the $(1240,2130)$-based iterative method, which we refer to as the $(1240,2130)$-Ite method.

We used the matchups of the in situ $R_{r s}(\lambda)$ measurements coincident with the MODIS-Aqua image pixels to assess the atmospheric correction results with these three methods. There are several requirements used to select the matchups of the in situ $R_{r s}(\lambda)$ measurements coincident with the MODIS-Aqua image pixels. First, the time difference between the in situ $R_{r s}(\lambda)$ measuring time and MODIS-Aqua image acquisition time should not exceed 3 hours. Second, the water should be stable within the time difference, that is, there should be no rain, and the wind speed should not exceed $5 \mathrm{~m} / \mathrm{s}$. Third, the MODIS-Aqua image pixels that surround the in-situ sampling sites should be cloudless and absent of high sunglint. Last, in the $3 \times 3$ window pixels of the retrieved $R_{r s}(\lambda)$ image that surrounds the sampling station coordinate, the number of valid positive pixels should exceed 5 and the coefficient of variation for the valid positive pixels should be smaller than $40 \%$.

To assess the accuracy of the $(1640,2130)$ and $(1240,2130)$-Ite methods, we used all matchups. To assess the accuracy of the $(1240,2130)$-Cal method, we divided the coincident matchups into both calibration matchup data, which were used in the vicarious calibration, and validation matchup data.

The accuracy parameters used in the accuracy assessment include the correlation coefficient ( $\mathrm{r}$ ), average relative error (ARE), root-mean-square deviation (RMSE), and relative root-mean-square deviation (rRMSE). The definitions of the ARE, RMSE, and rRMSE are as follows:

$$
\begin{gathered}
A R E=\frac{\sum_{1}^{N}\left|R_{r s}^{m}-R_{r s}^{i}\right|}{N} \\
R M S E=\sqrt{\frac{\sum_{1}^{N}\left(R^{m_{r s}}-R_{r s}^{i}\right)^{2}}{N}} \\
r R M S E=\sqrt{\frac{\sum_{1}^{N}\left(\frac{R^{m_{r s}}-R_{r s}^{i}}{R^{m}}\right)^{2}}{N}}
\end{gathered}
$$

where $R_{r s}^{m}$ and $R_{r s}^{i}$ are the in situ-measured and image-derived $R_{r s}$, respectively, and $\lambda$ is omitted.

\section{Results}

\subsection{Vicarious Calibration Results}

To perform the vicarious calibration of the MODIS-Aqua VIS-NIR bands, we used the coincident in situ $R_{r s}(\lambda)$ measurements with the eight scenes of the MODIS-Aqua images, including A20060090445, A20062110520, A20070080510, A20071160535, A20090730540, A20091070530, A20122920525, and A20142990510. Using the atmospheric parameters computed with the SeaDAS 7.2 and the in situ-measured $R_{r s}(\lambda)$, we calculated the $L_{t}(\lambda)$ in the eight VIS-NIR bands. Figure 3 shows the scatter plots of the computed $L_{t}(\lambda)$ and MODIS-measured $L_{t}(\lambda)$. By performing a regression between 
the computed $L_{t}(\lambda)$ and MODIS-measured $L_{t}(\lambda)$, we obtained the vicarious calibration results. Table 3 lists the "gain" of the eight VIS-NIR land bands.

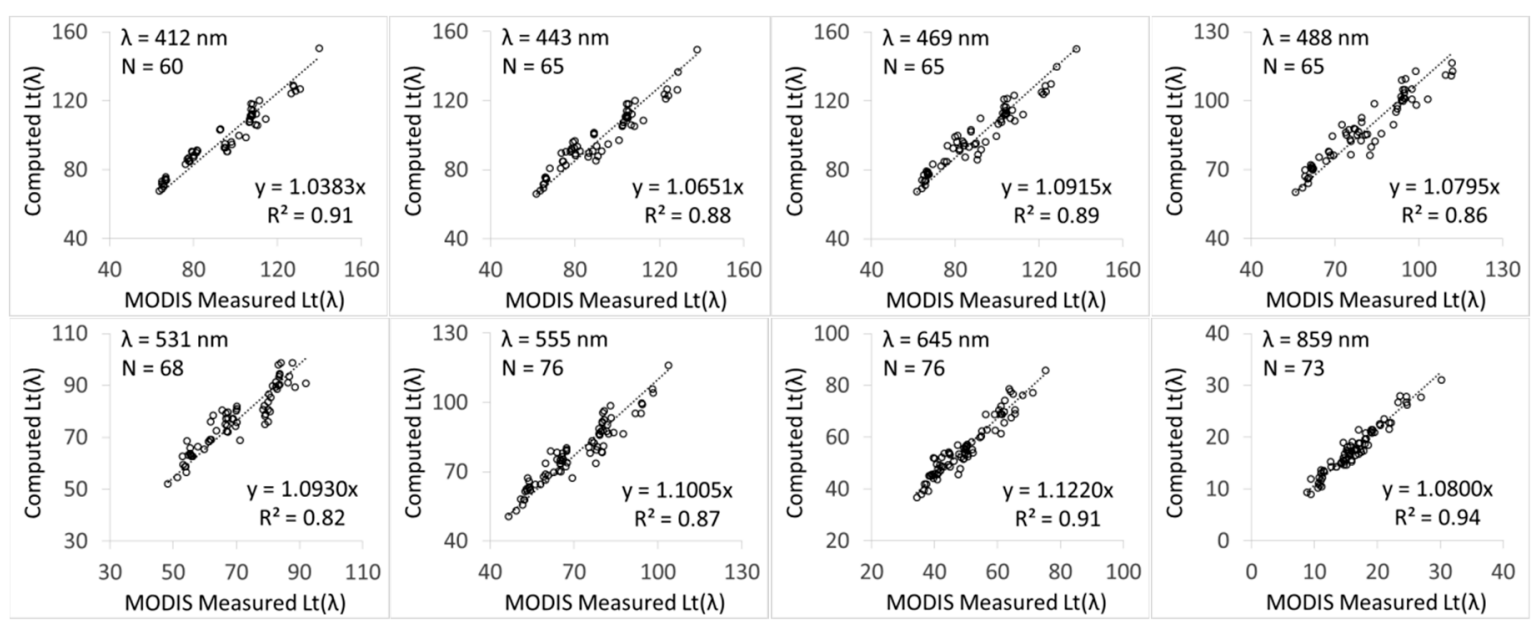

Figure 3. A comparison between the moderate resolution imaging spectroradiometer (MODIS)-Aqua measured $L_{\mathrm{t}}(\lambda)$ in Lake Taihu with the computed $L_{\mathrm{t}}(\lambda)$ via the in situ-measured $R_{r s}(\lambda)$ and atmospheric correction parameters calculated with the SeaDAS 7.2. The units for the MODIS-measured and computed $L_{\mathrm{t}}(\lambda)$ are $\mathrm{W} \mathrm{m} \mathrm{m}^{-2} \mu \mathrm{m}^{-1} \mathrm{sr}^{-1}$.

Table 3. The regional vicarious calibration results for the MODIS-Aqua visible and near infrared (NIR) bands using the in situ $R_{r s}(\lambda)$ in the highly turbid Lake Taihu with the $(1240,1640)$-based atmospheric correction algorithm. The default gains in SeaDAS 7.2 are also shown in this table.

\begin{tabular}{ccccccccc}
\hline Band $(\mathbf{n m})$ & $\mathbf{4 1 2}$ & $\mathbf{4 4 3}$ & $\mathbf{4 6 9}$ & $\mathbf{4 8 8}$ & $\mathbf{5 3 1}$ & $\mathbf{5 5 5}$ & $\mathbf{6 4 5}$ & $\mathbf{8 5 9}$ \\
\hline $\begin{array}{c}\text { gain } \\
\text { (This study) }\end{array}$ & 1.0383 & 1.0651 & 1.0915 & 1.0795 & 1.0930 & 1.1005 & 1.1220 & 1.0800 \\
\hline $\begin{array}{c}\text { gain } \\
\text { (SeaDAS 7.2 default) }\end{array}$ & 0.9722 & 0.9872 & 1.0139 & 0.9923 & 0.9995 & 1.0014 & 1.0253 & 1.0184 \\
\hline
\end{tabular}

\subsection{Atmospheric Correction Accuracy Assessment}

We compared the atmospheric correction accuracy of the three methods, i.e., the $(1640,2130)$, $(1240,2130)-$ Ite, and $(1240,2130)$-Cal. First, we computed their atmospheric correction accuracy with matchups for the in situ $R_{r s}(\lambda)$ measurements coincident with the MODIS-Aqua image pixels. Then, we further compared the typical atmospheric correction result images using the three methods.

\subsubsection{Comparison of Atmospheric Correction Accuracy}

Figure 4 shows the scatter plots for the matchups of the in situ $R_{r s}(\lambda)$ measurements coincident with the atmospheric correction results for the MODIS-Aqua using the three methods, i.e., the (1640, 2130), (1240, 2130)-Ite, and (1240, 2130)-Cal. The points for the (1240, 2130)-Cal results were divided into calibration points, referred to as $(1240,2130)$-Cal (Cal), and validation points, referred to as (1240, 2130)-Cal (Val). Table 4 lists the calculated ARE, RMSE, rRMSE, and r. The accuracy of the atmospheric correction results for the $(1240,2130)$-Cal method was computed using both validation and total matchups. 


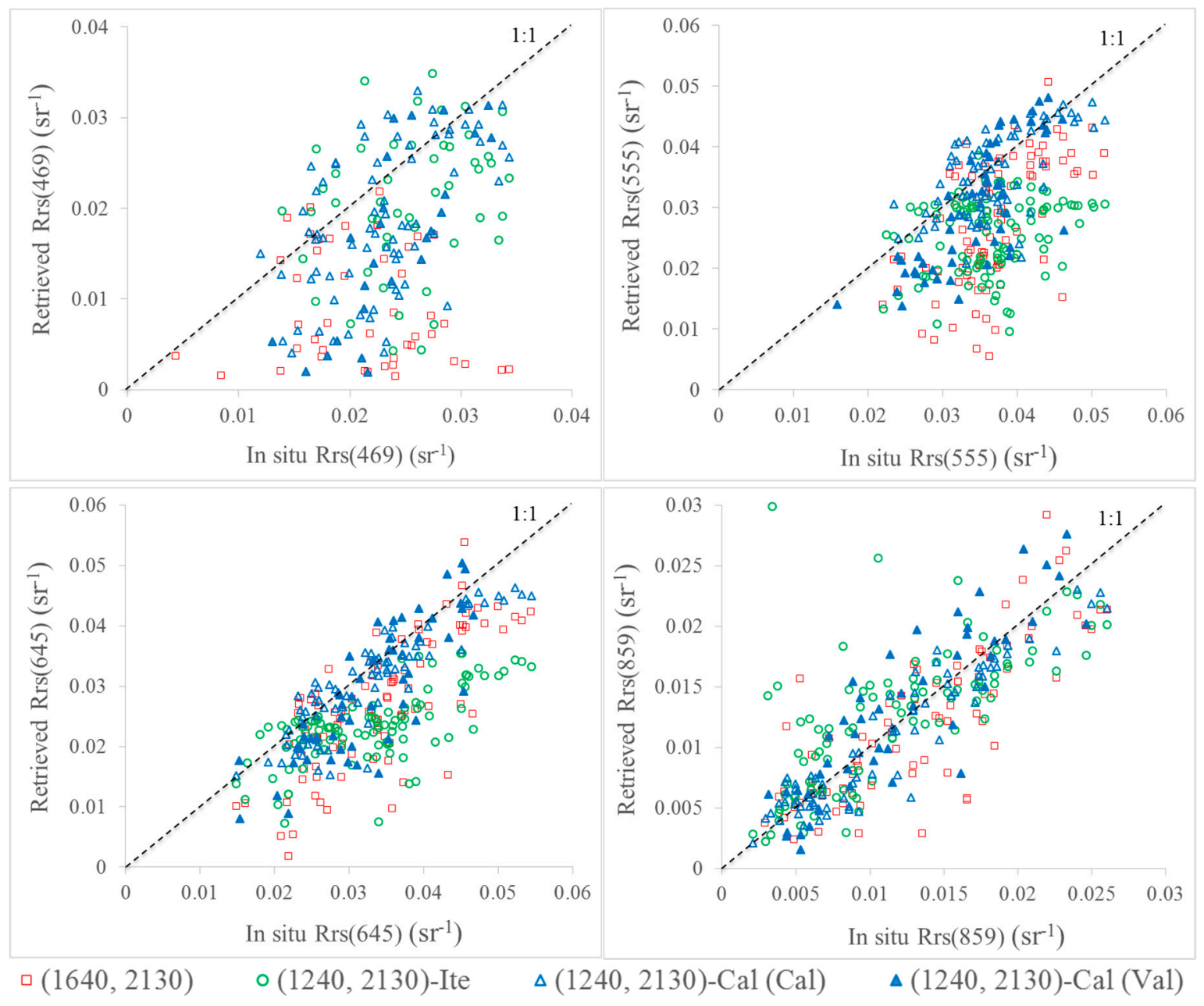

Figure 4. The scatter plots of the matchups for the in situ $R_{r S}(\lambda)$ measurements coincident with the atmospheric correction results of MODIS-Aqua based on the three methods, i.e., the $(1640,2130)$, $(1240,2130)-$ Ite, and $(1240,2130)$-Cal. The points for the $(1240,2130)$-Cal results were divided into calibration, referred to as $(1240,2130)$-Cal (Cal), and validation points, referred to as $(1240,2130)$-Cal (Val). Table 4 lists the valid matchup numbers for each band based on each method.

Based on Figure 4 , we observe that the $R_{r s}(\lambda)$ results from the $(1240,2130)$-Cal method are closer to the 1:1 line compared with the results from the $(1640,2130)$ and $(1240,2130)$-Ite methods. For the $R_{r s}(\lambda)$ results from the $(1240,2130)$-Cal method, the distribution of the calibration points (referred to as $(1240,2130)-\mathrm{Cal}(\mathrm{Cal}))$ are similar to those of the validation points (referred to as $(1240,2130)-\mathrm{Cal}(\mathrm{Val}))$. For the $R_{r s}(\lambda)$ results at different bands from the $(1240,2130)$-Cal method, the $R_{r s}(\lambda)$ values at the 555, 645 , and $859 \mathrm{~nm}$ bands are closer to the 1:1 line while the $R_{r s}(\lambda)$ results at the $469 \mathrm{~nm}$ band show a slight scatter.

We can further analyze the accuracy reported in Table 4. First, the valid matchup numbers from the $(1640,2130)$ method are the smallest, which is mainly due to the fact $70 \%$ of the detectors are inoperable in the $1640 \mathrm{~nm}$ band. Valid matchup numbers for the (1240, 2130)-Ite method are also smaller than those based on the $(1240,2130)$-Cal method, which is mainly due to the fact that the (1240, 2130)-Ite method does not work on several images absent of clear water. Therefore, the (1240, 2130)-Cal method yielded the most valid matchup numbers, which indicates that it is a more robust method. Second, for the ARE, RMSE, and rRMSE, the valid matchup numbers from the (1240, 2130)-Cal method are the smallest. Third, for $r$, the valid matchup numbers from the $(1240,2130)$-Cal method are the largest. Lastly, the difference between these accuracies for the (1240, 2130)-Cal (Total) and (1240, 
2130)-Cal (Val) methods are similar. Therefore, these results suggest that the (1240, 2130)-Cal method has the highest accuracy and robustness.

Table 4. The accuracy, based on the matchups, of the in situ $R_{r s}(\lambda)$ measurements coincident with the atmospheric correction results for MODIS-Aqua using the three methods, i.e., the $(1640,2130)$, $(1240,2130)$-Ite, and $(1240,2130)$-Cal. For the $(1240,2130)$-Cal, accuracies were computed for both the total and validation matchup data, which are reported as $(1240,2130)$-Cal (Total) and $(1240,2130)$-Cal (Val), respectively. The valid matchup numbers vary for the different bands and with respect to the atmospheric correction method because the valid atmospheric-corrected $R_{r s}(\lambda)$ value must be positive and the coefficients of variation must be smaller than $40 \%$ in the $3 \times 3$ window that surrounds the coincident in situ $R_{r s}(\lambda)$ measurements.

\begin{tabular}{|c|c|c|c|c|c|c|c|}
\hline Approach & Band (nm) & $\begin{array}{l}\text { Valid matchup } \\
\text { numbers }\end{array}$ & $\begin{array}{l}\text { Rrs range } \\
\left(\mathrm{sr}^{-1}\right)\end{array}$ & ARE & $\begin{array}{l}\text { RMSE } \\
\left(\mathbf{s r}^{-1}\right)\end{array}$ & rRMSE & $\mathbf{r}$ \\
\hline \multirow{4}{*}{$(1640,2130)$} & 469 & 50 & $0.004-0.035$ & $52 \%$ & 0.015 & $62 \%$ & 0.15 \\
\hline & 555 & 89 & $0.005-0.051$ & $28 \%$ & 0.013 & $35 \%$ & 0.58 \\
\hline & 645 & 92 & $0.002-0.054$ & $24 \%$ & 0.010 & $31 \%$ & 0.75 \\
\hline & 859 & 77 & $0.002-0.029$ & $26 \%$ & 0.004 & $41 \%$ & 0.81 \\
\hline \multirow{4}{*}{$(1240,2130)$-Ite } & 469 & 95 & $0.003-0.025$ & $29 \%$ & 0.009 & $36 \%$ & 0.25 \\
\hline & 555 & 112 & $0.010-0.039$ & $28 \%$ & 0.014 & $33 \%$ & 0.25 \\
\hline & 645 & 112 & $0.007-0.035$ & $26 \%$ & 0.012 & $31 \%$ & 0.67 \\
\hline & 859 & 109 & $0002-0.030$ & $40 \%$ & 0.006 & $96 \%$ & 0.69 \\
\hline \multirow{4}{*}{$\begin{array}{c}\text { (1240, 2130)-Cal } \\
\text { (Total) }\end{array}$} & 469 & 98 & $0.002-0.033$ & $33 \%$ & 0.009 & $40 \%$ & 0.58 \\
\hline & 555 & 129 & $0.014-0.048$ & $15 \%$ & 0.007 & $20 \%$ & 0.70 \\
\hline & 645 & 130 & $0.008-0.050$ & $14 \%$ & 0.006 & $19 \%$ & 0.84 \\
\hline & 859 & 122 & $0.002-0.028$ & $22 \%$ & 0.003 & $29 \%$ & 0.90 \\
\hline \multirow{4}{*}{$\begin{array}{c}(1240,2130)-C a l \\
\text { (Val) }\end{array}$} & 469 & 25 & $0.002-0.031$ & $39 \%$ & 0.010 & $47 \%$ & 0.78 \\
\hline & 555 & 51 & $0.014-0.048$ & $20 \%$ & 0.008 & $24 \%$ & 0.77 \\
\hline & 645 & 52 & $0.008-0.050$ & $18 \%$ & 0.007 & $24 \%$ & 0.83 \\
\hline & 859 & 46 & $0.002-0.028$ & $28 \%$ & 0.003 & $35 \%$ & 0.88 \\
\hline
\end{tabular}

\subsubsection{Comparison of Atmospheric-Corrected Images}

We used a scene of a MODIS-Aqua image, acquired on April 26, 2009, named A20091160520, to compare the atmospheric-corrected $R_{r s}$ images based on the (1640, 2130), (1240, 2130)-Ite, and (1240, 2130)-Cal methods. We set the spatial resolution of the atmospheric-corrected $R_{r s}$ result image at $250 \mathrm{~m}$. The $R_{r s}(645)$ and $R_{r s}(859)$ images had finer spatial patterns since their original spatial resolution was $250 \mathrm{~m}$ and did not require spatial interpolation. Figure 5 shows a comparison of the atmospheric-corrected $R_{r s}(645)$ and $R_{r s}(859)$ images based on the three different methods. There are five coincident in situ $R_{r s}$ measurements and Figure 5 a shows their locations as red dots. We further compared the five matchups of the in situ $R_{r s}$ spectra with the corresponding atmospheric-corrected $R_{r s}$ spectra in Figure 6. Table 5 lists the average ARE of these five matchups. 

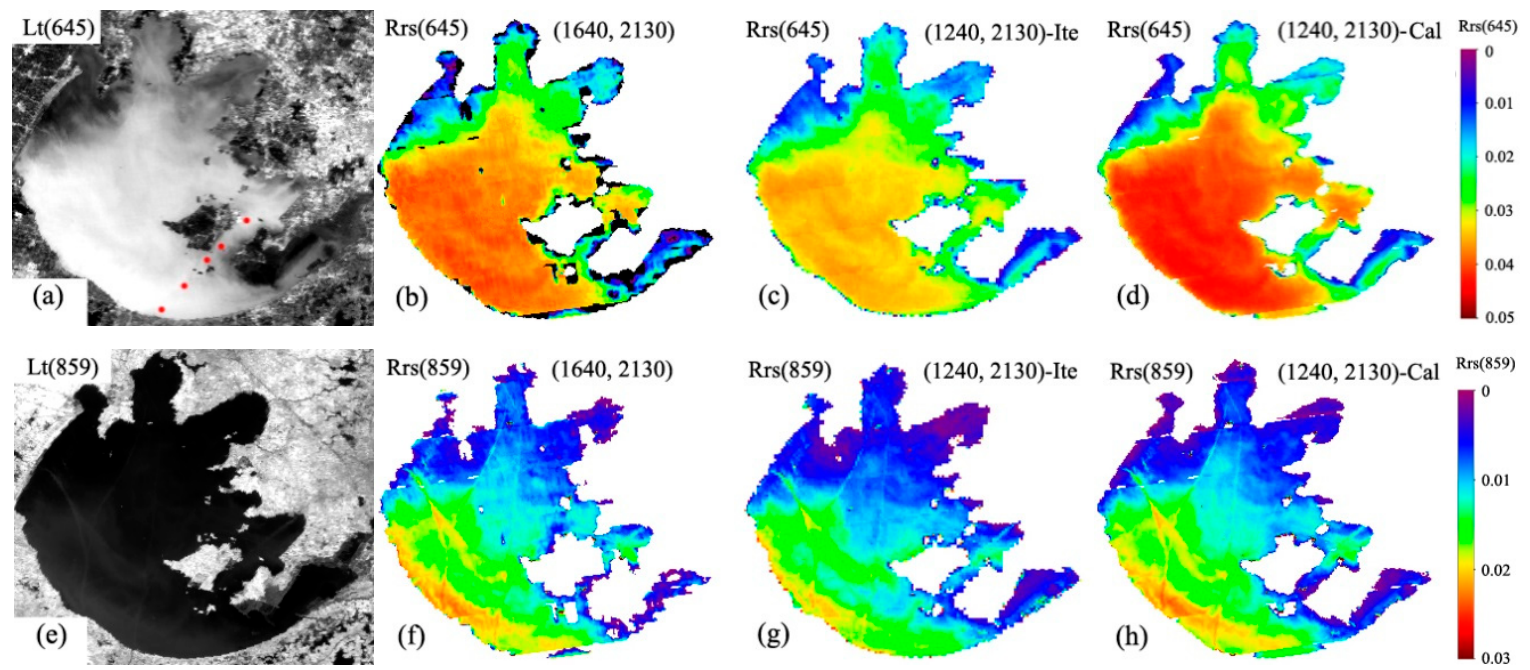

Figure 5. The atmospheric-corrected $R_{r s}$ images of a scene from a MODIS-Aqua image acquired on 26 April 2009, based on the $(1640,2130),(1240,2130)-I t e$, and $(1240,2130)$-Cal methods. (a) is the $L_{\mathrm{t}}(645)$ image, which shows the locations of the five coincident in situ $R_{r s}$ measurements as red dots. (b-d) are the atmospheric-corrected $R_{r s}(645)$ images based on the (1640, 2130), (1240, 2130)-Ite, and (1240, 2130)-Cal methods, respectively. (e) is the $L_{t}(859)$ image. (f-h) are the atmospheric-corrected $R_{r s}(859)$ images based on the $(1640,2130),(1240,2130)-I t e$, and $(1240,2130)$-Cal methods, respectively. The $(1240,2130)$-Cal method retrieved an AOT(555) $=0.33($ Mean $) \pm 0.10($ Std) .
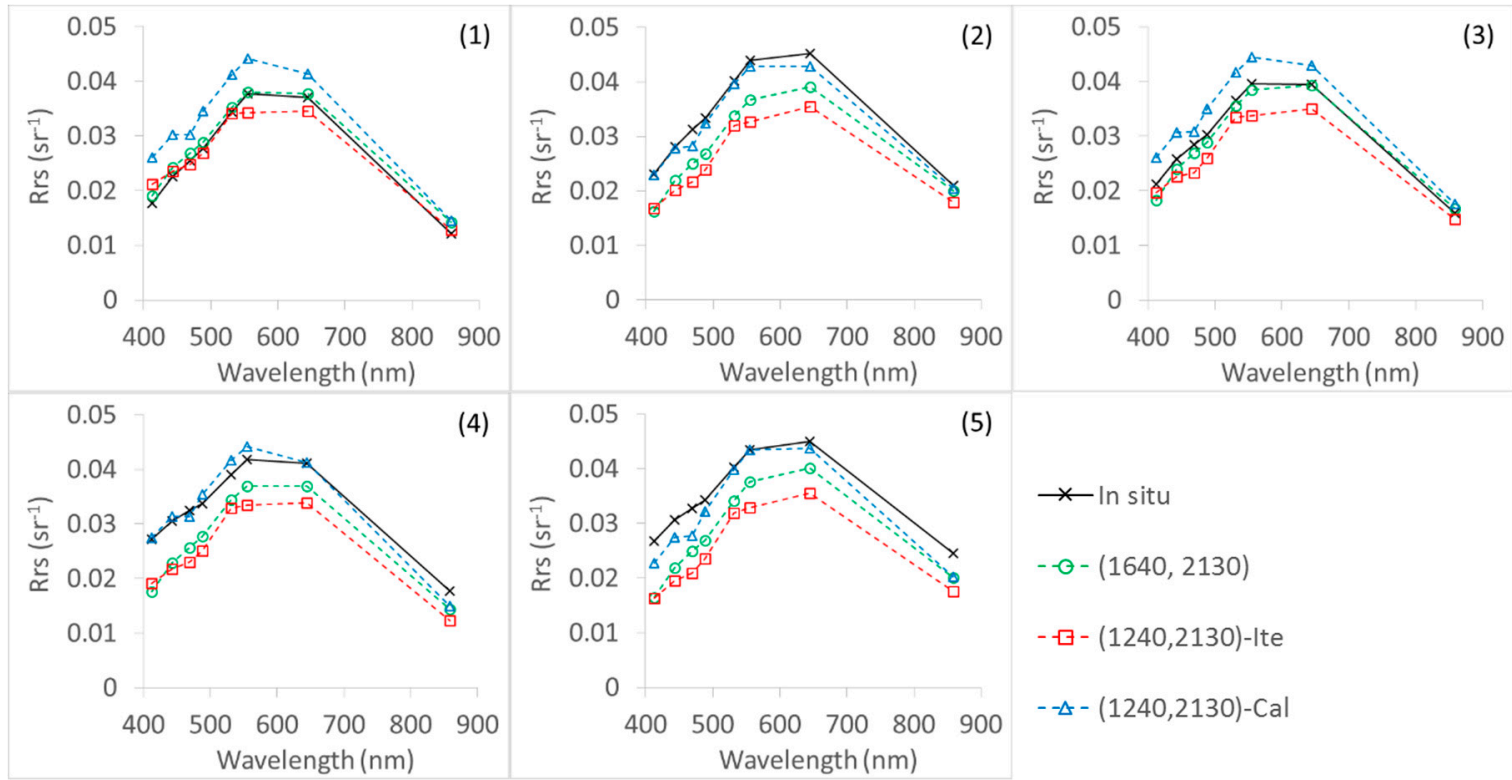

(5)

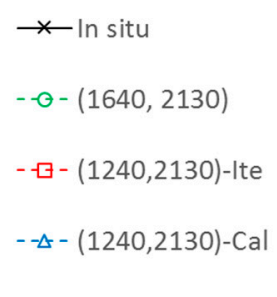

Figure 6. A comparison of the five matchups for the in situ $R_{r s}$ spectra with corresponding atmospheric-corrected $R_{r s}$ spectra from the MODIS-Aqua image acquired on 26 April 2009, which was processed using the three different methods. The five subfigures show the comparison results on the five in situ locations, the red dots in Figure 5 a. 
Table 5. The average relative error (ARE) of the five matchups for the in situ $R_{r s}$ spectra with the corresponding atmospheric-corrected $R_{r s}$ spectra from the MODIS-Aqua image acquired on 26 April 2009, processed using the three different methods.

\begin{tabular}{|c|c|c|c|c|c|c|c|c|c|}
\hline Approach $\quad$ Band(nm) & 412 & 443 & 469 & 488 & 531 & 555 & 645 & 859 & Mean \\
\hline$(1640,2130)$ & $25 \%$ & $18 \%$ & $15 \%$ & $13 \%$ & $10 \%$ & $9 \%$ & $7 \%$ & $13 \%$ & $14 \%$ \\
\hline$(1240,2130)$-Ite & $24 \%$ & $22 \%$ & $23 \%$ & $21 \%$ & $13 \%$ & $19 \%$ & $16 \%$ & $17 \%$ & $19 \%$ \\
\hline$(1240,2130)-\mathrm{Cal}$ & $17 \%$ & $14 \%$ & $11 \%$ & $11 \%$ & $9 \%$ & $7 \%$ & $6 \%$ & $13 \%$ & $11 \%$ \\
\hline
\end{tabular}

Based on Figure 5, we observe that there are similar spatial patterns in the retrieved $R_{r s}(645)$ and $R_{r s}(859)$ images from the different atmospheric correction methods. There is significant noise and areas of atmospheric correction failure in the retrieved $R_{r s}(645)$ and $R_{r s}(859)$ images from the (1640, 2130) method, which is mainly due to the inoperable detectors in the $1640 \mathrm{~nm}$ band. Most areas of the retrieved $R_{r s}(645)$ and $R_{r s}(859)$ images based on the $(1240,2130)$-Ite method were underestimated compared with those retrieved by the $(1640,2130)$ and $(1240,2130)$-Cal methods, which is possibly due to the inappropriate interpolation of aerosol models from clear water. Based on Figure 6, we observe that the $R_{r s}(\lambda)$ spectra retrieved by the $(1240,2130)$-Cal method are, overall, the closest to the in situ-measured $R_{r s}(\lambda)$ spectra, though the match-ups of (1) and (3) show a better correspondence with the $R_{r s}(\lambda)$ spectra retrieved by the $(1640,2130)$ method. This is also observable based on the average ARE listed in Table 5, which is $11 \%$ for the $(1240,2130)$-Cal method and $14 \%$ for the $(1640$, $2130)$ method. As for the retrieved $R_{r s}(\lambda)$ spectral shapes, the $(1640,2130)$ method retrieves even better spectral shapes than the $(1240,2130)$-Cal method. Considering all these factors, the results in Figures 5 and 6 and Table 5 indicate that the $(1240,2130)$-Cal method produces the best overall $R_{r s}(\lambda)$ results.

\section{Discussion}

\subsection{Effects of the BRDF Correction}

The SeaDAS 7.2 default BRDF correction model is the Morel f/Q model, which is an iterative model based on chlorophyll-a $[44,45]$. This model performs well in clear open ocean waters but has problems when applied to highly turbid coastal and inland waters [27]. We used a scene from a MODIS-Aqua image, acquired on 9 January 2006, named A20060090445, to discuss the BRDF problem.

We used the $(1240,2130)$-Cal approach to perform atmospheric correction of this image twice. We did not perform BRDF correction (brdf_opt $=0$ ) the first time, and for the second, we set the BRDF correction as the default value. Figure $7 \mathrm{~b}, \mathrm{c}$ show the atmospheric-corrected $R_{r s}(645)$ results with and without the default BRDF correction, respectively. We further show the BRDF correction factor in Figure 7d, which was computed during the atmospheric correction process with the default BRDF correction.

Based on Figure 7, we observe that the $R_{r s}(645)$ image without BRDF correction is smooth along the entire lake and the spatial pattern is similar to that of $L_{t}(645)$. The $R_{r s}(645)$ image with BRDF correction, however, has several clear jumps mainly located at the center and southwestern areas of the lake. By comparing these images with the BRDF correction factor image, these jumps occur at the edges of the black areas. The value of these black areas is zero, which indicates that the BRDF correction model failed in these areas and did not perform BRDF correction. Therefore, Figure 7 confirms that the SeaDAS 7.2 default BRDF correction is not suitable for highly turbid waters. Unfortunately, there are no other existing operational BRDF correction models for highly turbid waters.

Fortunately, due to the multi-scattering of light in highly turbid waters, the BRDF of highly turbid water is weaker than that of clear ocean water [27]. We can, therefore, temporally ignore the BRDF correction for highly turbid waters, especially when the viewing zenith angle is not large, which will yield reasonable atmospheric-corrected results. For image pixels with large viewing zenith angles, 
which can be obtained from the Hisatzen field in 12flags, the atmospheric-corrected results should be used cautiously.
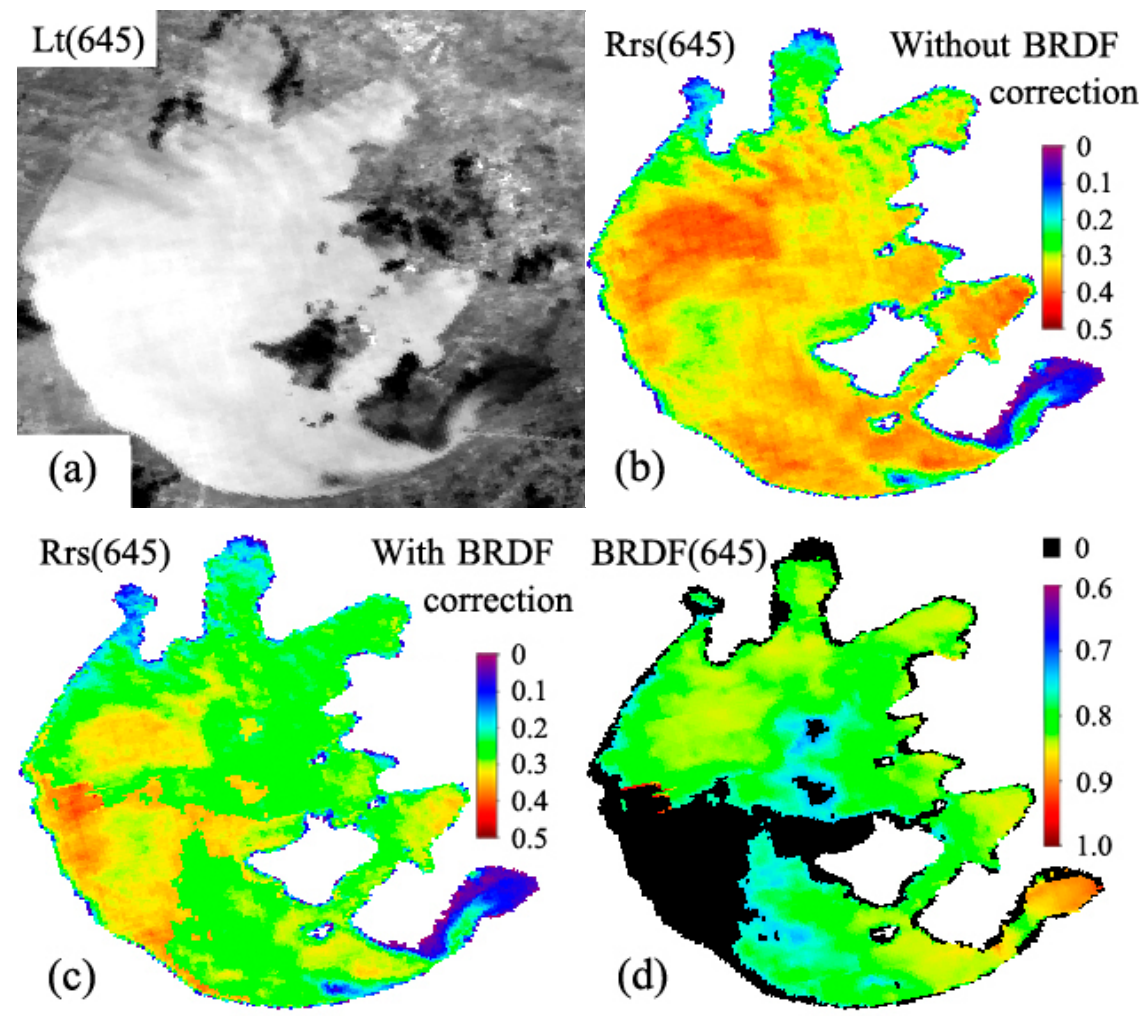

Figure 7. The atmospheric-corrected $R_{r s}(645)$ images of a scene of a MODIS-Aqua image acquired on 9 January 2006, using the $(1240,2130)$-Cal method. (a) is the $L_{t}(645)$ image. $(\mathbf{b}, \mathbf{c})$ are the atmospheric-corrected results without BRDF correction and with the default BRDF correction, respectively. (d) is the BRDF correction factor computed during the atmospheric correction process with the default BRDF correction.

\subsection{Uncertainty and Applicability Analysis}

Except for the BRDF correction, there are several other sources of error in the SWIR-based atmospheric correction method, including the noise in the SWIR bands, the inaccurate aerosol model, and other parameter settings in the SeaDAS 7.2, as well as the non-negligible water-leaving radiance in the $1240 \mathrm{~nm}$ band in certain extremely turbid waters. By incorporating the vicarious calibration results into the atmospheric correction process, these errors cancel out to some extent, especially in the macroscopic view. This suggests that the atmospheric-corrected results of a specific image may contain certain errors but that the vicarious calibration significantly cancels out the overall error.

The atmospheric corrections had better accuracy at the 555 (green light), 645 (red light), and $859 \mathrm{~nm}$ (NIR) wavelengths than those at the $469 \mathrm{~nm}$ (blue light) wavelength, which is possibly due to two reasons. On one hand, blue light is farther from the SWIR bands than the green, red, and NIR bands, such that the aerosol scattering errors are possibly due to derivation over a longer spectral distance because the errors associated with the SWIR bands, aerosol models, and other sources of error may increase during derivation over a long distance. On the other hand, in situ $R_{\mathrm{rs}}$ measurements are based on the above-water method and the determination of the skylight reflectance at the air-water interface, $r_{\text {sky }}$, which also has associated uncertainty. Since skylight has increased at the blue light wavelength, the error associated with determining $r_{\text {sky }}$ causes higher uncertainty in the computed $R_{\text {rs }}$ results for blue light. Therefore, the atmospheric-corrected $R_{\mathrm{rs}}$ results at $469 \mathrm{~nm}$ (blue light) should be used cautiously. While blue light is highly absorbed by high concentrations of suspended particulate matter 
and color dissolved organic matter (CDOM) in highly turbid waters, the $R_{\mathrm{rs}}$ for blue light is seldom used to retrieve chlorophyll-a and suspended particulate matter in highly turbid waters [28,29,46-48].

The vicarious calibration results are mainly applicable to Lake Taihu as these are based on the coincident in situ-measured $R_{r s}$ data from the lake; however, these may also be applicable to other highly turbid waters with similar optical and aerosol optical properties above water. Even if the calibration results may not be applicable to some waters, the procedure used in this study can be applied to these waters in general, by using the coincident in situ-measured $R_{r s}$ data from these waters to obtain new vicarious calibration coefficients. We expect to validate and extend the present approach to other highly turbid waters in the near future.

\section{Conclusions}

In this study, we performed regional vicarious calibration of the MODIS-Aqua SWIR (1240, 2130)-based atmospheric correction approach using the in situ water surface reflectance data measured in the highly turbid Lake Taihu during different seasons. We then verified the accuracy of the (1240, 2130)-based atmospheric correction approach with the vicarious calibrated results and compared the results with the other approaches. The main findings of this study are as follows.

First, the vicarious calibration was performed based on the in situ $R_{r s}$ measurements from Lake Taihu coincident with eight scenes of the MODIS-Aqua images. The obtained vicarious calibration coefficient gains for the eight MODIS-Aqua visible and NIR bands at 412, 443, 469, 488, 531, 555, 645, and $859 \mathrm{~nm}$ were $1.0383,1.0651,1.0915,1.0795,1.0930,1.1005,1.1220$, and 1.0800, respectively.

Second, through the regional vicarious calibration of the VIS-NIR bands, the $(1240,2130)$-based atmospheric correction approach yielded good results for the $R_{\mathrm{rs}}$ retrievals at the 555, 645, and $859 \mathrm{~nm}$ bands for Taihu Lake, with AREs of 15\%, 14\%, 22\% for the 555, 645, and $859 \mathrm{~nm}$ bands, respectively, with no significant bias.

Further comparison with the (1240, 2130)-based iterative approach (i.e., the (1240, 2130)-Ite) and the $(1640,2130)$-based approach showed that the vicarious calibrated $(1240,2130)$-based approach had the best accuracy and robustness.

Finally, our results suggest that the SeaDAS 7.2 default BRDF correction model is not suitable for highly turbid waters since it is weaker than that of clear ocean waters. Therefore, we do not recommend the use of the BRDF correction for the atmospheric correction of highly turbid waters.

These results show that the regional vicarious calibration of the $(1240,2130)$-based atmospheric correction approach is applicable to the highly turbid Lake Taihu. This approach may also be applicable to other highly turbid inland waters with similar optical and aerosol optical properties above water but requires further validation.

Author Contributions: Conceptualization, J.L.; formal analysis, Z.L., F.Z., and Q.S.; funding acquisition, B.Z.; methodology, J.L. and F.Z.; validation, Z.Y., Z.L., Y.Y., and Q.S.; writing—original draft, J.L.; writing-review and editing, Z.Y., Y.Y., and B.Z.

Funding: This study has been jointly sponsored by National Key Research and Development Program of China (2017YFC0405804), National Natural Science Foundation of China (41701402, 91638201, and 41571361).

Acknowledgments: The authors would like to thank NASA GSFC for providing MODIS-Aqua data, and thank Chuanmin Hu from University of South Florida for the help during the MODIS-Aqua data batch-processing.

Conflicts of Interest: The authors declare no conflict of interest.

\section{References}

1. Gordon, H.R.; Wang, M. Retrieval of water-leaving radiance and aerosol optical thickness over the oceans with SeaWiFS: A preliminary algorithm. Appl. Optics. 1994, 33, 443-452. [CrossRef] [PubMed]

2. McClain, C.R. A decade of satellite ocean color observations. Annu. Rev. Mar. Sci. 2009, 1, 19-42. [CrossRef] [PubMed]

3. Ruddick, K.G.; Ovidio, F.; Rijkeboer, M. Atmospheric correction of SeaWiFS imagery for turbid coastal and inland waters. Appl. Optics. 2000, 39, 897-912. [CrossRef] [PubMed] 
4. Siegel, D.A.; Wang, M.; Maritorena, S.; Robinson, W. Atmospheric correction of satellite ocean color imagery: the black pixel assumption. Appl. Opt. 2000, 39, 3582-3591. [CrossRef] [PubMed]

5. Stumpf, R.; Arnone, R.; Gould, R.W.; Martinolich, P.M.; Ransibrahmanakul, V. A partially coupled ocean-atmosphere model for retrieval of water-leaving radiance from SeaWiFS in coastal waters. NASA Tech. Memo. 2003, 206892, 51-59.

6. Lavender, S.J.; Pinkerton, M.H.; Moore, G.F.; Aiken, J.; Blondeau-Patissier, D. Modification to the atmospheric correction of SeaWiFS ocean colour images over turbid waters. Cont. Shelf. Res. 2005, 25, 539-555. [CrossRef]

7. Bailey, S.W.; Franz, B.A.; Werdell, P.J. Estimation of near-infrared water-leaving reflectance for satellite ocean color data processing. Opt. Express 2010, 18, 7521-7527. [CrossRef] [PubMed]

8. Hu, C.; Carder, K.L.; Muller-Karger, F.E. Atmospheric Correction of SeaWiFS Imagery over Turbid Coastal Waters: A Practical Method. Remote Sens. Environ. 2000, 74, 195-206. [CrossRef]

9. Wang, M.; Wei, S. Estimation of ocean contribution at the MODIS near-infrared wavelengths along the east coast of the US: Two case studies. Geophys. Res. Lett. 2005, 32, 370. [CrossRef]

10. Wang, M.; Shi, W. The NIR-SWIR combined atmospheric correction approach for MODIS ocean color data processing. Opt. Express 2007, 15, 15722-15733. [CrossRef]

11. Wang, M.; Liu, X. The MODIS-SWIR Algorithm Theoretical Basis Document Version 1.0. In NOAA NESDIS STAR; 2012; 40p. Available online: https://www.star.nesdis.noaa.gov/sod/mecb/color/documents/SWIR_ ATBD_ver1-2012.pdf (accessed on 1 July 2019).

12. Hale, G.M.; Querry, M.R. Optical Constants of Water in the 200-nm to 200- $\mu$ m Wavelength Region. Appl. Optics. 1973, 12, 555-563. [CrossRef] [PubMed]

13. Wang, M.; Tang, J.; Shi, W. MODIS-derived ocean color products along the China east coastal region. Geophys. Res. Lett. 2007, 34, L06611. [CrossRef]

14. Wang, M.; Son, S.; Shi, W. Evaluation of MODIS SWIR and NIR-SWIR atmospheric correction algorithms using SeaBASS data. Remote Sens. Environ. 2009, 113, 635-644. [CrossRef]

15. Wang, M.; Shi, W.; Tang, J. Water property monitoring and assessment for China's inland Lake Taihu from MODIS-Aqua measurements. Remote Sens. Environ. 2011, 115, 841-854. [CrossRef]

16. Zhang, M.; Ma, R.; Li, J.; Zhang, B.; Duan, H. A Validation Study of an Improved SWIR Iterative Atmospheric Correction Algorithm for MODIS-Aqua Measurements in Lake Taihu, China. IEEE. Trans. Geosci. Remote Sens. 2014, 52, 4686-4695. [CrossRef]

17. Wang, M.; Son, S.; Zhang, Y.; Shi, W. Remote Sensing of Water Optical Property for China's Inland Lake Taihu Using the SWIR Atmospheric Correction With 1640 and $2130 \mathrm{~nm}$ Bands. IEEE J. Sel. Topics Appl. Earth Observ. Remote Sens. 2013, 6, 2505-2516. [CrossRef]

18. Gordon, H.R. In-orbit calibration strategy for ocean color sensors. Remote Sens. Environ. 1998, 63, $265-278$. [CrossRef]

19. Wang, M. In-orbit vicarious calibration for ocean color and aerosol products. In Proceedings of the 2005 IEEE International Geoscience and Remote Sensing Symposium, 2005, IGARSS '05, Seoul, South Korea, 29 July 2005; 2005. [CrossRef]

20. Franz, B.A.; Bailey, S.W.; P Jeremy, W.; Mcclain, C.R. Sensor-independent approach to the vicarious calibration of satellite ocean color radiometry. Appl. Optics. 2007, 46, 5068-5082. [CrossRef]

21. Dash, P.; Walker, N.; Mishra, D.; D'Sa, E.; Ladner, S. Atmospheric Correction and Vicarious Calibration of Oceansat-1 Ocean Color Monitor (OCM) Data in Coastal Case 2 Waters. Remote Sens. 2007, 4, 1716-1740. [CrossRef]

22. Zibordi, G.; Mélin, F.; Voss, K.J.; Johnson, B.C.; Franz, B.A.; Kwiatkowska, E.; Huot, J.-P.; Wang, M.; Antoine, D. System vicarious calibration for ocean color climate change applications: Requirements for in situ data. Remote Sens. Environ. 2015, 159, 361-369. [CrossRef]

23. Wang, M.; Shi, W.; Jiang, L.; Voss, K. NIR- and SWIR-based on-orbit vicarious calibrations for satellite ocean color sensors. Opt. Express 2016, 24, 20437-20453. [CrossRef] [PubMed]

24. Li, J.; Hu, C.; Shen, Q.; Barnes, B.B.; Murch, B.; Feng, L.; Zhang, M.; Zhang, B. Recovering low quality MODIS-Terra data over highly turbid waters through noise reduction and regional vicarious calibration adjustment: A case study in Taihu Lake. Remote Sens. Environ. 2017, 197, 72-84. [CrossRef]

25. Concha, J.; Mannino, A.; Franz, B.; Bailey, S.; Kim, W. Vicarious calibration of GOCI for the SeaDAS ocean color retrieval. Int. J. Remote Sens. 2019, 40, 3984-4001. [CrossRef] 
26. Clark, D.K.; Gordon, H.R.; Voss, K.J.; Ge, Y.; Broenkow, W.; Trees, C. Validation of atmospheric correction over the ocean. J. Geophys. Res. - Atmos. 1997, 102, 17209-17217. [CrossRef]

27. Li, J.; Shen, Q.; Zhang, B.; Chen, D. Retrieving total suspended matter in Lake Taihu from HJ-CCD near-infrared band data. Aquat. Ecosyst. Health. 2014, 17, 280-289. [CrossRef]

28. Shi, K.; Zhang, Y.; Zhu, G.; Liu, X.; Zhou, Y.; Xu, H.; Qin, B.; Liu, G.; Li, Y. Long-term remote monitoring of total suspended matter concentration in Lake Taihu using 250m MODIS-Aqua data. Remote Sens. Environ. 2015, 164, 43-56. [CrossRef]

29. Zhang, B.; Li, J.; Shen, Q.; Chen, D. A bio-optical model based method of estimating total suspended matter of Lake Taihu from near-infrared remote sensing reflectance. Environ. Monit. Assess. 2008, 145, 339-347. [CrossRef]

30. Duan, H.; Ma, R.; Hu, C. Evaluation of remote sensing algorithms for cyanobacterial pigment retrievals during spring bloom formation in several lakes of East China. Remote Sens. Environ. 2012, 126, 126-135. [CrossRef]

31. Duan, H.; Ma, R.; Loiselle, S.A.; Shen, Q.; Yin, H.; Zhang, Y. Optical characterization of black water blooms in eutrophic waters. Sci. Total Environ. 2014, 482, 174-183. [CrossRef]

32. Sun, D.Y.; Yun, M.L.; Qiao, W.; Lv, H.; Cheng, F.L.; Chang, C.H.; Shao, Q.G. Detection of Suspended-Matter Concentrations in the Shallow Subtropical Lake Taihu, China, Using the SVR Model Based on DSFs. IEEE Geosci. Remote Sens. 2010, 7, 816-820. [CrossRef]

33. Hu, C.; Lee, Z.; Ma, R.; Yu, K.; Li, D. MODIS observations of cyanobacteria blooms in Taihu Lake, China. J. Geophys. Res. 2010, 115, 1-20. [CrossRef]

34. Le, C.; Li, Y.; Zha, Y.; Sun, D.; Huang, C.; Zhang, H. Remote estimation of chlorophyll a in optically complex waters based on optical classification. Remote Sens. Environ. 2011, 115, 725-737. [CrossRef]

35. Lyu, H.; Wang, Y.; Jin, Q.; Shi, L.; Li, Y.; Wang, Q. Developing a semi-analytical algorithm to estimate particulate organic carbon (POC) levels in inland eutrophic turbid water based on MERIS images: A case study of Lake Taihu. Int. J. Appl. Earth Obs. Geoinf. 2017, 62, 69-77. [CrossRef]

36. Ma, R.; Duan, H.; Lü, C.; Loiselle, S. Unusual links between inherent and apparent optical properties in shallow lakes, the case of Taihu Lake. Hydrobiologia 2011, 7, 49-158. [CrossRef]

37. Qi, L.; Hu, C.; Duan, H.; Cannizzaro, J.; Ma, R. A novel MERIS algorithm to derive cyanobacterial phycocyanin pigment concentrations in a eutrophic lake: Theoretical basis and practical considerations. Remote Sens. Environ. 2014, 154, 298-317. [CrossRef]

38. Mueller, J.L.; Morel, A.; Frouin, R.; Davis, C.; Arnone, R.; Carder, K.; Lee, Z.P.; Steward, R.G.; Hooker, S.; Holben, B.; et al. Ocean optics protocols for satellite ocean color sensor validation, Revision 4, Volume III: radiometric measurements and data analysis protocols. Natl. Aeronaut. Space Adm. Rep. 2003, 21621, 1-72.

39. Mobley, C.D. Estimation of the remote-sensing reflectance from above-surface measurements. Appl. Optics. 1999, 38, 7442-7455. [CrossRef]

40. Sun, D.; Li, Y.; Le, C.; Shi, K.; Huang, C.; Gong, S.; Yin, B. A semi-analytical approach for detecting suspended particulate composition in complex turbid inland waters (China). Remote Sens. Environ. 2013, 134, 92-99. [CrossRef]

41. Zhang, F.; Li, J.; Qian, S.; Bing, Z.; Wu, C.; Wu, Y.; Wang, G.; Wang, S.; Lu, Z. Algorithms and Schemes for Chlorophyll a Estimation by Remote Sensing and Optical Classification for Turbid Lake Taihu, China. IEEE J. Sel. Topics Appl. Earth Observ. Remote Sens. 2017, 8, 350-364. [CrossRef]

42. Shen, Q.; Li, J.; Zhang, F.; Sun, X.; Li, J.; Li, W.; Zhang, B. Classification of Several Optically Complex Waters in China Using in Situ Remote Sensing Reflectance. Remote Sens. 2015, 7, 14731-14756. [CrossRef]

43. Gordon, H.R.; Voss, K.J. MODIS Normalized Water-Leaving Radiance, Algorithm Theoretical Basis Document (MODIS 18); Version 5; University Miami: Coral Gables, FL, USA, 2004.

44. Morel, A.; Gentili, B. Diffuse reflectance of oceanic waters. III. Implication of bidirectionality for the remote-sensing problem. Appl. Optics. 1996, 35, 4850-4862. [CrossRef] [PubMed]

45. Morel, A.; Antoine, D.; Gentili, B. Bidirectional reflectance of oceanic waters: accounting for Raman emission and varying particle scattering phase function. Appl. Optics. 2002, 41, 6289-6306. [CrossRef] [PubMed]

46. Wang, H.; Hladik, C.M.; Huang, W.; Milla, K.; Edmiston, L.; Harwell, M.; Schalles, J. Detecting the spatial and temporal variability of chlorophyll-a concentration and total suspended solids in Apalachicola Bay, Florida using MODIS imagery. Int. J. Remote Sens. 2010, 31, 439-453. [CrossRef] 
47. Le, C.; Hu, C.; English, D.; Cannizzaro, J.; Chen, Z.; Feng, L.; Boler, R.; Kovach, C. Towards a long-term chlorophyll-a data record in a turbid estuary using MODIS observations. Prog. Oceanogr. 2013, 109, 90-103. [CrossRef]

48. Nechad, B.; Ruddick, K.G.; Park, Y. Calibration and validation of a generic multisensor algorithm for mapping of total suspended matter in turbid waters. Remote Sens. Environ. 2010, 114, 854-866. [CrossRef]

(C) 2019 by the authors. Licensee MDPI, Basel, Switzerland. This article is an open access article distributed under the terms and conditions of the Creative Commons Attribution (CC BY) license (http://creativecommons.org/licenses/by/4.0/). 